\title{
Forest Ecosystems in a Changing Environment: what are future monitoring and research needs?
}

Trees are long-living organisms, and forest ecosystems therefore need to be adapted to changing environmental conditions. The environmental conditions that are affecting forests and the societal demands on forests are, however, changing at an ever rapid rate. Will forest ecosystems and their management be able to adapt? Which information on both, the changing environment and forest condition, do we need to answer this question? How can forest monitoring and the research on reactions of forests to environmental change best be integrated? Is the current effort in forest monitoring in Europe sufficient to answer the new emerging questions, and how can it be improved?

These were the questions that were addressed at the strategic COST workshop 'Forest ecosystems in a changing environment: identifying future monitoring and research needs' in Istanbul, Turkey, 11 to 13 March 2008. No less than 170 experts discussed the above questions with regard to the following environmental challenges: climate change (both the reaction of forests to climate change and the mitigating potential of forests as carbon sinks), continued high nitrogen and acidic deposition loads leading to eutrophication and soil acidification, continued exceedance of critical ozone concentrations, increasing $\mathrm{CO} 2$ concentrations.

The workshop was financially supported by the COST European Cooperation in the Field of Scientific and Technical Research. It was jointly organized by the Johann Heinrich von Thünen Institute - Federal Research Institute for Rural Areas, Forestry and Fisheries, Institute for World Forestry (Mr. Richard Fischer and Dr. Martin Lorenz), the Ministry of the Environment and Forestry General Directorate of Forestry, Turkey (Mr. Ismail Belen), the International Union of Forest Research Organizations R.G. 7.01-00 - Impacts of air pollution and climate change on forest ecosystems (Dr. Elena Paoletti), The European Commission - DG Joint Research Centre Institute for Evironment and Sustainability, Land Management and Natural Hazards Unit (Dr. Jesus San-Miguel-Ayanz) and the European Environmental Agency (Dr. Tor-Björn Larsson).

The key recommendations of the workshop were:

- to encourage more integrated research, monitoring and modelling approaches in the fields of climate change, pollutant deposition, ground-level ozone and biodiversity;
- to study and monitor more thoroughly the biological reactions of mature forests to climate change;

- to increase assessments and measurements of water availability in forests and related meteorological conditions;

- to improve ozone risk assessment of plants, moving from a concentration-based to a flux-based approach;

- to substantiate effects of critical load exceedances, including dynamical modelling;

- to improve the research of element fluxes as a key element in understanding effects of disturbance on forests;

- to increase the use of existing data and facilities for a more integrated assessment of biodiversity indicators;

- to implement consistent quality assurance programs to help guarantee the efficient use of financial resources;

- to further implement a coherent and integrated multifunctional forest monitoring system;

- to improve and extend the accessibility and evaluation of existing forest monitoring systems;

- and to expand the regional coverage of research activities and monitoring.

The three papers presented in this issue of annals of forest science cover a selection of the aspects discussed during the workshop. A summary of the findings and recommendations of the workshop can be found in Fischer (2008). Until now critical levels of ozone to plants are based on the AOT40 approach, which is the sum of hourly exceedances of $40 \mathrm{ppb}$. However, the AOT40 gives no information on the actual uptake of ozone in plants, because uptake is a function of ozone concentrations and stomata opening. As ozone flux into the plant cannot readily be measured ozone uptake models are needed as is presented by Tuovinen et al. (this issue). The interactive effects of ozone, rising $\mathrm{CO}_{2}$ concentrations and recent warming on tree establishment at the sensitive tree line were reviewed by Wieser et al. (this issue). 
Long-term monitoring on a continental scale encompasses many countries and research entities. It poses special needs on data quality, in particular sampling design, comparability and reliability of data and data management, i.e., storage and evaluation. Quality assurance of all aspects of data assessment and gathering is, therefore, extremely important. The implementation of quality assurance and possible improvements in two large-scale monitoring networks (ICP Forests in Europe and EANET in south-east Asia) is presented by Ferretti et al. (this issue). Further results of the workshop were also published online in separate articles in iForest - Biogeosciences and Forestry, vol. 2, pp. 1-55.

\section{REFERENCES}

Fischer R. (Ed.), 2008. COST strategic workshop forest ecosystems in a changing environment: identifying future monitoring and research needs, Istanbul, Turkey, Report and recommendations. Institute for world forestry, Hamburg, $26 \mathrm{p}$.

Matthias Dobbertin, Associate editor and special section editor Swiss Federal Research Institute WSL, Birmensdorf, Switzerland 